IJ§ER

ISSN: 2149-5939
International Journal of Social Sciences and Education Research

Online, http://dergipark.gov.tr/ijsser

Volume: 3(3), 2017

\title{
Marie Luise Kaschnitz'in “Lange Schatten” adlı öyküsünde benlik sorunu
}

\author{
The self problem in the story of "Lange Schatten" by Marie Luise Kaschnitz
}

\author{
Zennube Şahin Yilmaz ${ }^{1}$
}

\begin{abstract}
Received Date: 02 / 02 / 2017
Accepted Date: 05 / $06 / 2017$

$\ddot{O} z$

Savas öncesi daha çok kadını ele alan romanları ile savaș sonrası da savașın etkilerini konu edinen başarılı șiirleriyle dikkat çeken Marie Luise Kaschnitz, öykülerinde sunduğu sosyo-psikolojik konular ile edebiyat dünyasinda önemli yer edinmiştir. Özellikle bireylerin/çocukların duygu ve düşünce dünyasına tanık ettiği metinleri, hem toplumsal hem de psikolojik açıdan incelenmeye uygun bir zemin sunmuştur. Kaschnitz'in yapitları, ruhsal dünyaya dair birçok veri sunması bakımından psikolojik tartışmalara olanak sağlamıştır.

Çalışmamızda ele aldığımız "Lange Schatten” adlı öykü, hem psikolojik hem de sosyolojik bir incelemeye uygundur. Başkişi olarak seçilen küçük bir kız çocuğun ruh dünyası ve aile ortamındaki sıkıntıları detaylı bir biçimde ele alınmıştır. Ailenin çocuğa yaklaşımı ve bu yaklaşımdan dolayı çocuğun yaşadıkları öykünün merkezinde yer almış ve olumsuz bir yönde geliş̧im gösteren/Benlik sorunu yaşayan çocuğun çizdiği olumsuz tablo göz önüne serilmiştir
\end{abstract}

Anahtar sözcükler: Aile-Çocuk İlişkisi, Benlik Sorunu, Kişilik Bozukluğu

\begin{abstract}
Marie Luise Kaschnitz, who, after the war, draws attention with her successful poems about the effects of war, and novels dealing more with women before the war, has had an important place in the world of literature with the socio-psychological issues presented in her stories. Texts which the individuals/children have especially witnessed in the world of emotion and thought presented a suitable ground for analysis both socially and psychologically. Kaschnitz's works have enabled psychological discussions in terms of presenting a lot of data about the spiritual world. The story "Lange Schatten" discussed in our work is suitable for both a psychological and a sociological examination. The difficulties in the spiritual world and the family environment of a little girl, who was selected as a protagonist, are touched upon in detail. Family's approach to the child and child's experiences due to this approach are at the center of the story and the negative picture drawn by the child who has developed in a negative direction/had an ego problem has been exposed.
\end{abstract}

Keywords: Family-Child Relationship, the Problem of Self, Personality Disorder

\section{Giriş}

Marie Luise Kaschnitz, şiir, drama, kısa öykü, günlük, deneme, roman gibi birçok türde yapıtlar veren bir yazar olarak, çoğunlukla genel bir konuyu özel bir bakış açısıyla/kişisel bir perspektifle ele alır. Daha çok kişisel bir bakış açısının hakim olduğu metinlerinde, anlatıcının veya figürün görüş/yorum bildiren tutumları dikkat çeker. Figürleri genel olarak kendi kendileriyle bir tartışma/yargılama içindedirler. Bu yüzden metinlerinde ana hatlarıyla kişisel bir eleştiri yer alır. 1950'li yıllarda ünlenen Kaschnitz'in öykü bandı "Lange Schatten (1960)" ve şiir bandı "Dein Schweigen - meine Stimme (1962)", onun Alman edebiyatında önemli bir yere sahip olmasında etkili olmuştur. (Ranicki, 2014).

\footnotetext{
${ }^{1}$ Yrd. Doç. Dr., Atatürk Üniversitesi, Edebiyat Fakültesi, Alman Dili ve Edebiyatı Bölümü, Erzurum/TÜRKIYYE, zsahin@atauni.edu.tr
} 
Şahin Yılmaz, Z (2017). Marie Luise Kaschnitz'in "Lange Schatten” adlı öyküsünde benlik sorunu. International Journal of Social Sciences and Education Research, 3(3), 957-965.

Kaschnitz, çoğunlukla bir dönem eleştirisinin yer aldığı yapıtlarında, Wilhelm İmparatorluğuna, Weimar Cumhuriyetine, 2. Dünya Savaşına ve bu savaşın yıkıntılarına eleştirel bir yaklaşım sergiler. Bu tür dönem olaylarının yer aldığı yapıtları, modern insanın değerlerini kaybetmesi ve kişiliksizleşme gibi konuları da ele alır. (Beierlieb, 2002).

\section{Kaschnitz'in yazın dünyası/konuları}

Her iki savaşı yaşayan bir yazar olan Kaschnitz'in yapıtları, özellikle Nasyonal Sosyalizmin izlerini taşır. O, yapıtlarında dönem özelliklerinin ve Nasyonal Sosyalist öğelerin dışında otobiyografik öğelere de yer verdiği için okurları onun hayatını çoğunlukla kısa öykülerinden öğrenme firsatı bulur. Hatta metinlerinde aile, kardeş ve anne ilişkilerini de ele alan Kaschnitz'in daha 4 yaşındayken bir kardeşinin dünyaya gelmesi ve kardeşini inanılmaz derecede kıskanması, öykülerine konu olmuştur. Bu kıskançlık duygusu ve aile içinde dışlanmışlık hissi birçok öyküsünde otobiyografik bir özellik olarak yer almıştır. Bu yüzden öyküleri, kişisel duygu durumlarına dair ayrıntılı bilgi verir (Kaminski, 2009).

Özellikle savaş sonrası edebiyata dahil olan şiirlerinde bir teselli arayışının hakim olması ilginçtir. Çünkü neredeyse 2. Dünya Savaşından sonra kaleme aldığı bütün şiirlerinde bir yıkıntı tablosu çizer. Kaschnizt'in zamanı önemseyen bu yönü, onu dönemini ön planda tutan ve bu dönem olaylarına kayıtsız kalmayan çağdaş bir yazar kategorisine dahil eder. O, döneminde gerçekleşen olayları konu olarak yapıtlarına taşımayı bir görev olarak algılar (Hahn, 2001).

$\mathrm{O}$, savaş sonrası liriğin temsilcisi olarak görülmüştür. Yapıt kronolojisinden hareketle, onun şiirlerini 1945 sonrası şiir devrimi olarak değerlendirenler olmuştur. Şiirlerinde dönemle bir tartışma içinde olduğu açıktır. Güncel toplumsal konuları detaylı duygu aktarımı ile birleştirmiştir. Öykülerinde ise toplumsal konularla birlikte bireysel/ruhsal sıkıntıları da ele almıştır. (Fenner, 2015).

\section{3. "Lange Schatten" Rosie ve benlik sorunu}

Kaschnitz'in bir öykü kitabına ismini veren "Lange Schatten" adlı öyküsü, Rosie adında bir kız çocuğunun Benlik sorununu aile üyeleri ile açığa kavuşturur. Öykü, yer yer o-anlatıcı yer yer de Rosie'nin bakış açısından aktarılır. Kaschnitz, tasvir ettiği aile tablosu içinde Rosie'nin dünyasını ön planda tu tarak bir aktarım sergiler. Öyküdeki diğer figürler de yine Rosie'nin bakış açısından verilir. Ebeveynlerin ve Rosie'nin tek başına kurmak istediği kendi dünyası yine kendisinin kişisel görüşü ile ele alınır.

Başkişi Rosie'nin “Sıkıcı, her şey sıkıcı, (..)” (Ranicki, 1994, s.341) ifadeleriyle başlayan öykü, daha ilk cümlesinde negatif bir ruh halinin sinyalini vermiş olur. Öykü, bir kumsalda başlar. Bir ailenin tatil yaptığ kumsalda anne, baba, Rosie ve Rosie'nin kız kardeşinden bahseden anlatıcı, bu aile tablosu içinde Rosie'ye yüklenen sorumluluğu şu şekilde aktarır; "Rosie, hiçbir zaman ebeveynleri ile yüzmeye gidemez, o bu sırada henüz küçük olan, ama artık tatlı olmayan, aksine bütün kumu kitaba sıçratan budala bir kaz ya da çıplak sırtının üzerinde yatan denizanası gibi olan kız kardeşine bakmak zorundadır." (Ranicki, 1994, s.341) Rosie'nin kız kardeşine dair yaptığı benzetmeler, aslında onun kız kardeşine yaklaşımına bir göndermede bulunur. Rosie, annesi ve babasıyla yüzmeye gidememesinden kız kardeşini sorumlu tutar. Bu yüzden de ona olan bakış açısı değişir. Kız kardeşini onu annesinden ve babasından ayıran ve onlarla zaman geçirmesini engelleyen bir varlık olarak görür. Bu bağlamda, Rosie'nin kız kardeşini kıskanması ve ailesinin 
Şahin Yılmaz, Z (2017). The self problem in the story of "Lange Schatten" by Marıe Luise Kaschnitz, International Journal of Social Sciences and Education Research, 3(3), 957-965.

bu tutumundan yakınması, ebeveynlerin çocuklar üzerindeki dengeyi sağlıklı bir biçimde kuramamasından kaynaklandığı düşünülebilir. Çünkü çocuğun hem psikolojik hem de fiziksel gelişiminde aile içindeki psikolojik atmosfer oldukça önemlidir. Ebeveynlerin çocuk üzerindeki tutum ve davranışları, çocuğun tutum ve davranışlarında yönlendirici olur. Ailenin yaklaşımı, çocuğuna gösterdiği ilgi/ilgisizlik aslında çocuğun da ailesine olan yaklaşımını belirler. (Sümer \& Aktürk \& Helvac1, 2010). Bu bağlamda Rosie de ailesinden gördüğü ilgi kadar ailesine ilgi gösterir ve ana hatlarıyla ailesinden uzak durmak isteyen bir kız çocuğu profili çizer.

Bir öğle yemeğinden sonra annesi, babası ve kız kardeşi uyurken, Rosie yola koyulur ve kendi kendisine "Ben kendi yoluma gideceğim, (...)" (Ranicki, 1994, s.341) der. Cadde boyunca yürüyen Rosie, yalnız olmanın keyfini çıkarır. Sadece yalnız olduğunda her şeyin sadece ona ait olduğunu düşünür. "İnsan yalnız olduğunda her şey büyür ve tuhaflaşır ve sadece bir kişiye ait olmaya başlar, benim caddem, benim siyah uyuz olmuş kedim, benim ölü kuşum, iğrenç, karıncalar tarafindan yenilmiş, ama kesinlikle elime almalıyım, benim.” (Ranicki, 1994, s.341) Rosie, yalnız olduğunda kendisini özgür hisseder ve gördüğü her şeyin kendisine ait olduğunu düşünerek, bundan mutlu olur. Onun bakış açısı ilginçtir. Çünkü aidiyet duygusu ile sıkıntı yaşamaktadır. Aidiyet temel bir insan gereksinimi olarak duyguları, davranışları ve ruh halini etkiler. Sevme/sevilme, saygı duyma/saygı duyulma, bağlı olmak/bağlanılma kişinin psikolojik yönünün sağlıklı gelişebilmesi için büyük bir önem teşkil eder. Aidiyet duygusunun olmaması, kişinin içine kapanarak yalnızlaşmasına, çevresine yabancılaşmasına ve bununla birlikte birtakım ruhsal sıkıntılara neden olur. (Duru, 2015). Rosie ise annesinden ve babasından bir yakınlık göremediği için kendisini o aileye ait hissetmez ve kendi aidiyetini önemser. Sadece kendisine ait olan bir dünya kurmak ister. Ancak kurduğu bu dünyada, kendisinin bir yere ya da kişiye ait olma fikrinden hoşlanmaz. Aslında Rosie'nin bu şekilde hissetmesinde ana etken annesi ve babasıdır. Çünkü onlar, sadece kendilerini düşünen ve çocuklarına yük muamelesi yapan kişilerdir. Bu yüzden de Rosie, sürekli benim vurgusunu yapar. Ayrıca alıntıda dikkat çeken başka bir nokta ise Rosie'nin benim diye adlandırdığı şeylerin hep olumsuz özelliklere sahip olmasıdır. Yukarıdaki alıntıda "Benim siyah uyuz olmuş kedim, benim ölü kuşum, iğrenç, karıncılar tarafından yenilmiş, ama kesinlikle elime almalıyım, benim." (Ranicki, 1994, s.342) şeklinde ifade ettiği cümleler, onun olumsuz bakış açışına işaret eder. Hayata bakış açısı negatif bir yönde olan Rosie, sahip olduğu nesnelere de bakış açısından/yaklaşımından dolayı olumsuz özellikler yükler. Bir kız çocuğunun sahip olması gereken sevecenliğe/sevgiye sahip değildir, Rosie. Bu olumsuz bakış açısı, bütün öyküde hissettirilmiştir. Hatta Rosie'nin ailesine dair dile getirdiği cümleleri de bu bağlamda hem dikkat çekici hem de öykünün iletmek istediği mesajı verir niteliktedir; "Bir aileye sahip olmak korkunç, başka insanlar da aileden yakınıyorlar, Rosie bunu oldukça açık bir biçimde görüyor, örneğin; bronzlaşmış altın kolyeli adam, güneş şemsiyesi altında yatmak yerine barda oturur ya da motorlu botu ile delice heyecanlara, son derece hızlı, daima yalnız gider. Aile bir eziyet, neden insan yetişkin olarak dünyaya gelemez ve hemen kendi yolunda gidemez." (Ranicki, 1994, s.341)

Aileyi bir yük olarak değerlendiren Rosie, ailesi olduğu için mutsuz bir kız çocuğudur. Çünkü o, ailesinden destek görmeyen ve daima yalnız bırakılan bir figür olarak karşımıza çıkar. Kendi annesinden ve babasından ilgi görmeyen Rosie, etrafındaki aileleri gözlemler ve onların da mutsuz olduğunu görür. Kendi ailesiyle başka aileleri karşılaştırır. Ancak bu aileler karşısında gördükleri genel olarak aynı çizgide birleşir; ilgisizlik. Rosie de ailesinin ilgisizliğinden dolayı küçük yaşta Ben olmaya çalışır ve Ben olma yolunda sıkıntı yaşar. Ergenlik döneminde olan bir çocuğun benlik gelişiminin sağlıklı olması, anne ve babaya bağlıdır. Çocuğa değer verilme derecesi ile ilgili olarak gelişen benlik, anne ve babanın çocuğa yaklaşımı ve çocuğun kendisini tanımasıyla 
Şahin Yılmaz, Z (2017). Marie Luise Kaschnitz'in "Lange Schatten” adlı öyküsünde benlik sorunu. International Journal of Social Sciences and Education Research, 3(3), 957-965.

birleşir. Bu birleşim sağlıklı olduğunda çocuğun sosyalleşmesi de ruh sağlığı da sağlıklı bir yönde gelişim gösterir. (Tözün, 2010). Bu bağlamda, aile içinde Rosie'ye verilen değer, onun sağlıklı/sağlıksız bir yönde gelişimine işaret eder. Ailesi tarafından çok önemsenmeyen Rosie, bu yüzden küçük yaşta bağımsız olma/ben olma sıkıntısı yaşar. Bu benlik sorunun somutlaştığı başka bir kesit ise Rosie'nin gözlemlediği her şeyi kendisine ait görmeye başlamasıdır; "Benim marketim, benim şehrim, bir sürü lastik oyuncaklarla dolu benim dükkanım, (..)” (Ranicki, 1994, s.343) Ben bilincinin aileden bağımsız bir şekilde gelişmesi Rosie'nin aslında sağlıksız kişilik gelişimine işaret eder. Bu bağlamda Karen Horney, kişinin sağlıklı olmayan kişilik ya da benlik gelişiminin çocukluk yıllarına dayandırır. Horney'e göre aile içinde yeterince ilgi görmeyen ve sevgi ihtiyacını karşılayamayan çocukta benlik gelişimi sağliklı bir yönde ilerlemez. (Aslan, 1992). Horney'in bu düşüncesinde hareket edildiğinde Rosie'nin aile içinde yeterince sevgi görmemesinin onda bu şekilde sağlıksız bir benlik gelişimine neden olduğu söylenilebilir.

Öyküde Rosie'nin aile ile olan ilişkisine ve bu ilişkiden dolayı Rosie'nin yaşadığ $\breve{g}_{1}$ Benlik s1kıntısına tanık olurken, aynı zamanda Rosie'nin çıktığı gezintide yaşadıklarını/gözlemlerini de öğrenme firsatı buluruz. Cadde boyunca yürümeye devam eden Rosie, etrafinda neler olduğunu izler ve yanından gelip geçenleri gözlemler. Onun yanından geçen gençler için ifade ettiği şu cümleler, oldukça dikkat çekicidir; "Genç adamlar burada sırnaşık tembeller, bunun için insanın aileye ihtiyacı yok, (...)” (Ranicki, 1994, s.343) Rosie'nin alıntıda dile getirdiği düşüncesi yine aile birliğine karşı bir ifadedir. Karşılaşıtığı her şeyi aileye bağlayan Rosie'nin bu tutumu onun aile birliğine karşı olmasıyla ilintilidir. O, aileyi her defasında yok saymaya çalışır ve kendisini aileden bağımsız bir birey olarak düşünür. Rosie, yine bir kesitte ebeveynlerinden bahseder "Aşağıda denizde, sadece Rosie'nin kaldığı yerde ebeveynler ikinci kez yüzüyorlar, o okul arkadaşları için sadece manzara resmi almak istemişti." (Ranicki, 1994, s.349) Anlatıc1, burada Rosie'nin yalnız kaldığı bir anı aktarır. Öyküde Rosie'nin ebeveynlerinden bahsedildiği hemen hemen bütün kesitlerde onun yalnızlığına göndermede bulunulur. Çünkü Rosie, ebeveynleri tarafından yalnız bırakılmış ve bu yüzden sağlıksız bir benlik psikolojisine bürünmüştür. Bu durumda aile üyelerinin büyük bir payı vardır. Çünkü, sevgi ve şefkat içinde büyüyen çocuklar, olumlu bir yönde kendilik/benlik geliştirirler. Ancak güvensiz, iletişimsiz, sevgisiz bir aile içinde büyüyen çocuklar, olumsuz bir yönde gelişim gösterirler. (Aktaş, 2011). Nitekim Rosie de ailesinden kaynaklanan bir soğukluk yaşar ve bu yüzden onlardan uzak durur, bu durum da onun yalnız kalmasına neden olur.

Rosie, yalnız yaptığı gezinti boyunca gördüklerinden memnun kalır. Yalnızlıkta mutlu olduğunu hisseder, aslında yalnız olmak, annesinden ve babasından ayrıca da sorumluluğunu üstlenmek zorunda kaldığı kız kardeşinden uzak olmaktır onun için. Gezdiği yerlerin biri, ona ailesini hatırlatır; "Burada yukarıdan ileriye doğru ebeveynler birlikte bir gezinti yapmayı planladılar, onların şimdi bu dağın arkasında karanlık odalarında yataklarında yatmaları sakinleştirici, Rosie başka bir ülkede, benim yă̆ ormanım, benim portakal ağacım, benim denizim, benim küçük köpeğim, bana taşı geri getir." (Ranicki, 1994, s.345) Rosie yukarıdaki alıntıda olduğu gibi kendisini başka bir dünyada hisseder. Rosie'nin yalnız olduğundaki bakış açısı oldukça olumlu bir tablo çizer. Bu olumlu tablo, ailesi ile olduğunda hemen değişir ve olumsuz bir yöne gider. Rosie, ebeveynlerine dair bir anısını hatırladığı kesitte yine ailesi ile olan ilişkisine dair bir resim çizer; "Rosie, bir keresinde ebeveynlerini ve kız kardeşini gerçekten unuttu, hem kendisini bir kişi olarak hem de isim ve yaş olarak, öğrenci Rosie Walter, lisenin 7. Sınıfında, daha çok çaba sarf etmeliydi, (...)" (Ranicki, 1994, s.346) Rosie'nin bu tutumu ailesine olan mesafesine işaret eder. 
Şahin Y1lmaz, Z (2017). The self problem in the story of "Lange Schatten" by Marie Luise Kaschnitz, International Journal of Social Sciences and Education Research, 3(3), 957-965.

Sağlıklı bir çocuğun ya da bireyin ailesini unutması olası bir durum değildir. Ancak Rosie, onları yok saymak istediği için bilinçli bir şekilde onları hatırlamak istemediği düşünülebilir.

Öykünün önemli bir kesiti, Rosie'nin ailesinden habersiz yaptığı bu gezide karşılaştığı genç ile olan diyaloğudur. Yürüyüşü sırasında karşılaştı bir gençle konuşan Rosie, gencin tavrı karşısında şaşırır, hatta onun ne yapmaya çalıştığını çözmek ister; "O neydi, o ne istiyor? diye düşündü Rosie.” (Ranicki, 1994, s.347) Anlatıcı, Rosie ve bu genç arasındaki diyaloğu verirken gencin yaşına dair tahminde bulunur; "Muhtemelen 12 yaşında, bir çocuk." (Ranicki, 1994, s.347) Rosie, genç çocuğu anlamaya çalışır, fakat onun tavırlarını tuhaf bulur. Hatta gencin aslında çocuğun Rosie'ye ifade ettiği şu cümleler onun hayatına dair ipuçları verir; "Bana gelin, lütfen beni kucaklayın, lütfen, öpün lütfen, sevin lütfen, (...)” (Ranicki, 1994, s.347) Çocuğun bu ifadeleri onun sevgiye muhtaç olduğuna işaret eder. Onun kendisinden daha büyük birinden bu şekilde ricada bulunması, sevgi/şefkat eksikliğini gösterir. Nitekim genel olarak çocuk, anneden ve babadan sevgi ve ait olma duygularını alır. Hatta ailenin çocuğunu sahiplenmesi, çocukta özgüven duygusunun gelişmesinde ve çocuğun sevgi/şefkat içinde büyüyüp sağlıklı bir kişi olmasında önemli bir rol oynar. Çocuğun yetersiz sevgi içinde büyümesi, çocukta sağlıksız psikososyal gelişimlere neden olur ve çocuk kendisiyle ailesiyle barışık bir dünyada yetişmez. (Şahin, 2014). Yukarıdaki alıntıda da çocuğun sevin beni diye haykırması, onun sevgiye muhtaçlığına iyi bir örnek oluşturur. Bu noktadan hareketle, çocuğun aile içinde görmediği sevgiyi dışarıda aradığı ve bu sevgi açlığını gidermeye çalıştığı söylenilebilir. Rosie, çocuğun bu tavrı karşısında biraz korkar, "Saçma, aklına ne geldi, sen kaç yaşındasın?” (s.348) şeklinde gülerek ve aynı zamanda korkarak tepki gösterir. Kendi kendisine, "Bana dokunamaz, bana hiçbir şey yapamaz, (...)" (Ranicki, 1994, s.348) şeklinde düşünen Rosie, bu durum karşısında tedirgin olur. Rosie'nin kendi kendisine ifade ettiği bu cümleleri iç monolog özelliğine de bir örnek oluşturur. İç monolog, bir kişinin içinden geçenleri sessiz bir şekilde ifade etme biçimi olarak değerlendirilir. Düşüncelerin ve duyguların direkt olarak dışa vurumudur. Kişi, karşılıklı bir diyalog içinde imajı vererek, düşüncelerini sessiz bir şekilde ifade eder. (Borchmeyer, Zmegac, 1994). Öyküde, yukarıdaki alıntıda olduğu gibi Rosie'nin bu iç monolog özelliğine örnek oluşturacak, kendi kendisine düşündüğü birçok kesit söz konusudur. Çocuğun karşındaki tepkisini bu iç monolog ile ifade eder, Rosie. Öyküde Rosie'nin u şekilde kendi kendisine düşündüğü ve sessiz bir iç konuşma yaptığ 1 birçok kesit söz konusudur. Çünkü Rosie, ailesiyle bir hesaplaşma içindedir. Bu hesaplaşma da en iyi onun iç dünyasını sessiz bir diyalog ile dışa vurması ile açığa çıkmıştır.

Rosie, bu gençle tanıştıktan sonra yaşadıklarını farklı bulur. Hatta çocuğun Rosie'nin karşısında soyunması, onu korkutur; "Her şey yeni, bu sıcak, parlak öğleden sonra her şey uyanık, yeni tecrübeler, hayat sevgisi, arzu ve utanç, bu çocuklar, ilkbaharın gelişi, ama sevgisiz, sadece özlem ve korku." (Ranicki, 1994, s.351) Rosie'nin hayata bakış açısı yalnız yaptığı bu yürüyüş sırasında değişir. Alıntıda ifade ettiği ama sevgisiz bölümü aslında Rosie'nin içinde bulunduğu sevgisizliğe işaret eder. Rosie, ailesinden bu kadar çok kaçmak isterken karşılaştığı bu durumda babasının yaptığ 1 tavsiyeleri hatırlar ve o tavsiyeler doğrultusunda hareket eder. Ailesini yok saymak isterken babasının tavsiyesine uyar. Gencin üzerine çıkarıp tamamen çıplak bir şekilde denize girmesi ve Rosie'ye yaklaşmaya çalışması karşısında Rosie, genci parlayan dişlerinden dolayı bir kurda benzetir; "Hayvanlar karşı insan kendisini koruyabilir, Rosie'nin zayıf gögüslü babası bunu bir kere yaptı, ama Rosie, o zaman küçüktü, bunu unutmuştu ama şimdi tekrara aklına geldi. Hayır, çocuk, taş yok, insanlar sabit bir biçimde köpeklerin gözüne bakmalı, gözüne tam dik, görüyor musun, titriyor, yere basar, kaçar.” (Ranicki, 1994, s.350) 
Şahin Y1lmaz, Z (2017). Marie Luise Kaschnitz'in "Lange Schatten” adlı öyküsünde benlik sorunu. International Journal of Social Sciences and Education Research, 3(3), 957-965.

Rosie de babasının köpeğe yaptığı gibi, gence dik dik bakar ve babasının bu öğüdünden yararlanır. Genç, bunun üzerine kıyafetlerini giyer ve bir yere oturur. Rosie, babasının tavsiyesine uyarak, içinde bulunduğu bir sıkıntıdan kurtulmuş olur. Burada ilginç olan nokta, Rosie'nin bir yandan ailesini yok saymaya çalışması bir yandan da babasının tavsiyesine uymasıdır. Aslında bu alıntıda verilmek istenilen en önemli mesaj, bir çocuğun ailesinden uzaklaşma çabalarının başarılı bir sonu vermeyeceğidir. Çünkü Rosie, gezintisinin sonunda yine babasının öğüdüne gelir. Rosie, ailesinden uzaklaşarak bağımsızlığının tadını çıkarmak isterken, çocuğun ona yaklaşımından rahatsız olur. Çocuk ise Rosie'nin karşısından soyunarak kendisini gösterme ve beğendirme çabası içine girer. Ancak bu durumda Rosie'den beklediği tepkiyi alamaz ve utancından ne yapacağını şaşırır. Rosie, gördüklerinden utanır, genç ise yaptıklarından. Bu sahneden sonra hem Rosie hem de çocuk, geri dönmek için yola koyulurlar. Anlatıcının hem Rosie'nin hem de gencin gidişini aktarma biçimi ilginçtir; "Zaman geçti, güneş dağların üzerine eğik vuruyor ve hem Rosie hem de genç yürürken uzun gölgeler oluşturuyorlar, uzun, birbirinden oldukça uzakta gölgeler, (...)" (Ranicki, 1994, s.352) Öykü, anlatıcının bu cümleleri ile son bulurken, öykünün başlığı olan uzun gölgeler ifadesi de ilk kez bu alıntıda geçmiş olur. Yolları birbiriyle kesişen Rosie ve gencin birlikte geçirdikleri bir öğleden sonra öykünün sonunda ayrı biter. Her ikisi de farklı bir yöne gider ve Rosie, bu süre içinde ailesinden uzak bir macera yaşamış olur.

\section{Sonuç}

Marie Luise Kaschnizt'in küçük bir kız çocuğunun gözleminden/perspektifinden aktardığı bu öykü, hem aile hem de çocuk açısından olumlu bir tablo çizmemiştir. Öyküde söz konusu edilen problem, kız çocuğunun ailesinden yeterince ilgi ve alaka görmediği için onlardan bağımsız bir hayat istemesi ile başlamıştır. Kendisinin ailesi tarafından anlaşılmadığı düşüncesinde olan Rosie, onlarla olmaktan sıkılmıştır. Ancak, burada önemli olan nokta Rosie'nin tanıştı̆̆ çocukla geçirdiği süredir. Çünkü ailesinden uzak bir maceraya atılmak isteyen Rosie, bu bağlamda macerayı korkuyla bitirmiştir. Rosie'nin yaşadığı bu macerada, ailesinden yeterince sevgi görememesinin ve kendisini dışlanmış hissetmesinin önemli bir payı olmuştur.

Kaschnitz, bu konu ile aslında öyküsünde kendi hayatından bir kesit sunmuştur. Çünkü o da Rosie gibi çocukluğunda kız kardeşini kıskanmış ve ailesiyle bu yüzden sıkıntı yaşamıştır. Bu yüzden, yazarın Rosie'yi donatırken ona kendi hayatından bir özellik yüklediği açıkça görülmüştür. Bu durum da otobiyografik bir veri olarak karşımıza çıkmıştır.

Öykü, ailenin tutumunun dışında, ergenlik çağında iki gencin aslında kendisilerini keşfetmesini ve bu keşfetme sırasında karşılaştığı problemleri de konu edinmiştir. Merkez noktasında anne/baba/çocuk ilişkisi yer alan bu öyküde çocuğun duygu durumu baskın bir şekilde açığa çıkarılmıştır. Anne-baba için normal karşılanan bir davranış biçiminin çocuk üzerinde bıraktığı olumsuz iz ve aslında çocuğun içinde bulunduğu duygusal boşluk, kişisel bir bakış açısından aktarılmıştır.

\section{Kaynakça}

Aktaş, S. (2011). 9. Sinıfta Anne Baba Tutumları ve Benlik Saygısı Arasındaki IIlişkinin Bazı Değişkenler Açısından İncelenmesi. Yüksek Lisans Tezi - Konya: Selçuk Üniversitesi Eğitim Bilimleri Enstitüsü.

Aslan, E. (1992). Benlik Kavramı ve Bireyin Yaşamındaki Etkileri, M.Ü. Atatürk Eğitim Fakültesi-Eğitim Bilimleri Dergisi, Sayı: 4, 7-14

Beierlieb, B. (2002). Interpretation des Gedichts "Nicht gesagt" von Marie Luise Kaschnitz. Germany: Grin Verlag. 
Şahin Yılmaz, Z (2017). The self problem in the story of "Lange Schatten" by Marıe Luise Kaschnitz, International Journal of Social Sciences and Education Research, 3(3), 957-965.

Borchmeyer, D., Zmegac, V. (1994). Moderne Literatur in Grundbegriffen. 2. Auflage, Tübingen: Max Niemeyer Verlag.

Duru, E. (2015). Genel Aidiyet Ölçeğinin Psikometrik Özellikleri: Geçerlik ve Güvenirlik Çalışması. Türk Psikolojik Danışma ve Rehberlik Dergisi. 5 (44), 37-47

Fenner, A. M. (2015). Trauer in der deutschen Nachkriegslyrik Zur Emotionsgestaltung bei Günter Eich, Marie Luise Kaschnitz und Nelly Sachs. Göttingen: Georg-August-Universität.

Hahn, H. (2001). Ästhetische Erfahrung als Vergewisserung menschlicher Existenz, Kunstbetrachtung im Werk von Marie Luise Kaschnitz. Würzburg: Königshausen\&Neumann.

Kaminski, K. (2009). Wege der Emanzipation: bedeutende Frauen im 20. Jahrhundert; zehn biographische Essays. Würzburg: Königshausen\&Neumann.

Ranicki, M. R. (1994). Deutsche Erzähler des 20. Jahrhunderts von Joseph Roth bis Hermann Burger. Zürich: Manesse Verlag.

Ranicki, M. R. (2014). Meine Geschichte der deutschen Literatur: Vom Mittelalter bis zur Gegenwart. München: Deutsche Verlags-Anstalt.

Sümer, N., Aktürk Gündoğdu, E., Helvacı, E. (2010). Anne-Baba Tutum ve Davranışlarının Psikolojik Etkileri: Türkiye'de Yapılan Çalışmalara Toplu Bakış. Türk Psikoloji Yazıları, 13 (25), 42-59

Tezel Şahin, F. (2014). Anne Çocuk İlişkisi ve Bu İlişkiyi Etkileyen Faktörler, International Journal of Science Culture and Sport (IntJSCS), ISSN: 2148-1148 - Doi: 10.14486/IJSCS203, 79-88

Tözün, M. (2010). Benlik Saygısı Benlik Saygısı, Geniş Açı-Actual Medicine. 
Şahin Yılmaz, Z (2017). Marie Luise Kaschnitz'in "Lange Schatten” adlı öyküsünde benlik sorunu. International Journal of Social Sciences and Education Research, 3(3), 957-965.

\section{Extended abstract in English}

Marie Luise Kaschnitz was born in Karlsruhe and she lived a long time in Postdam, Berlin, Marburg and Frankfurt. She began to write at an early age. She is novelist, poet and short story writer. She has made a significant/important career after 1945 with writing. Her literature offers a social, historical and melancholic atmosphere. She published her first novel Beginning Love (Liebe beginnt) in 1933 and later in 1937 her second novel Elissa. She starts to become famous with these works. She is also a successful autor in the fiel of poetry. She is in a discussion with the period in the large number of her poems. In fact, she was seen as the representative of the postwar poetry. Marie Luise Kaschnitz's works include human condition and age criticism.

Marie Luise Kaschnitz, who, after the war, draws attention with her successful poems about the effects of war, and novels dealing more with women before the war, has had an important place in the world of literature with the socio-psychological issues presented in her stories. She is an important writer in postwar German literature. Her postwar works reflect political situation in Germany. She is opposed to trying to forget the past. Her works include especially traces of National Socialism. She struggled with Germany's fascist past in her works and she wrote over the one hundred short stories. Kaschnitz's stories are generally about herself and her texts reflect her literary conception. Texts which the individuals/children have especially witnessed in the world of emotion and thought presented a suitable ground for analysis both socially and psychologically. Kaschnitz's works have enabled psychological discussions in terms of presenting a lot of data about the spiritual world. Readers often find the opportunity to learn her life from short stories, as it also includes autobiographical items. Some of her autobiographical works covers social problems, psychology of the individual, freedom of the individual and the problems of women in society.

Kaschnitz published in 1960 a collection of short stories Long Shadows (Lange Schatten). This story by Kaschnitz is one of the most important stories in German literature. Thus, she began to be seen as a short story writer with this work. The story of "Lange Schatten", which gave a name to Kaschnitz's story book, clarifies a girl's self - problem with family members. The little girl's world is in the foreground in this family and the story is transmitted from the observation / perspective of a little girl child. In the story, there is no positive picture for both the family and the child. The story "Long Shadows/Lange Schatten" discussed in our work is suitable for both a psychological and a sociological examination. The narrator in Kaschnitz's story is a child and from the point of view of this narrator learn the reader this story. This story shows the loneliness of a little girl. Feeling of belonging to a family suppresses the little girl and she has experienced psychologically negative process. Individual relationships, influence of the feeling, loneliness and psychological factors are discussed through a litte girl. The writer embodied narrative techniques (Internal monologue), while conveying the child's feelings. So narrative techniques take an important place to make emotions clear in story. Kaschnitz shows in this story the relationship between child and parents and the devolepment of the self. She has presented a section of her life in this story. Because, like the little girl in the story, the writer also had troubles with her family in her childhood. Kaschnitz makes the subject in this story the problems with her sister and family. This feeling of jealousy and the feeling of being excluded from the family are some of autobiographical features in this story. The writer characterized the little girl with the same features as herself. For this reason the autobiographical features in the story stand out clearly and attracted the reader. In this story, that the mother / father / child relationship at the center is, has been 
Şahin Y1lmaz, Z (2017). The self problem in the story of "Lange Schatten" by Marie Luise Kaschnitz, International Journal of Social Sciences and Education Research, 3(3), 957-965.

dominantly revealed.the child's emotional state. Kaschnitz texts are witnessing the reader to personal emotional states of the figures.

In this study, I have discussed the importance of emotional and individual/personal devolepment of a litte girl. The difficulties in the spiritual world and the family environment of a little girl, who was selected as a protagonist, are touched upon in detail. Family's approach to the child and child's experiences due to this approach are at the center of the story and the negative picture drawn by the child who has developed in a negative direction/had an ego problem has been exposed. 